\title{
MANAJEMEN MULTIKULTURAL DALAM BERPOLITIK
}

\author{
Khairiah \\ Institut Agama Islam Negeri (IAIN) Bengkulu \\ Jalan Raden Fatah, Kota Bengkulu, Bengkulu \\ Pos-el: khairiah@iainbengkulu.ac.id
}

\begin{abstract}
The purpose of this paper is to describe multicultural management in politics. The method used is descriptive qualitative approach. The component that becomes the benchmark is impact analysis, due to politics in the lives of multicultural communities in Indonesia, as a basis for providing opinions or conclusions about a process and system of political activities in cultural diversity in multicultural societies in order to maintain the integrity of the Unitary Republic of Indonesia (NKRI), Pancasila, The 1945 Constitution and Unity in Diversity. This article discusses multicultural management programs in politics. The results show that multicultural management as a management of outlook on life can realize political awareness. With multiculturalism, it can give birth to views and a healthy political system, so as to create a sense of security, comfort and peace in the life of the nation and state, so the author can suggest if you want the political conditions to take place safely, peacefully and harmoniously, then enhance multicultural management in society.
\end{abstract}

Keywords: Multicultural; Management; Politics

Abstrak: Tujuan penulisan ini untuk mendeskripsikan manajemen multikultural dalam berpolitik. Metode yang digunakan pendekatan kualitatif deskriptif. Komponen yang menjadi tolak ukur adalah analisis dampak, akibat perpolitikan dalam kehidupan masyarakat multikultural di Indonesia, sebagai dasar pemberian opini atau kesimpulan mengenai suatu proses dan system kegiatan perpolitikan dalam keberagaman budaya dalam masyarakat multicultural demi menjaga keutuhan Negara Kesatuan Republik Indonesia (NKRI), Pancasila, Undang-undang Dasar 1945 dan Bhinneka tunggal ika. Artikel ini membahas program manajemen multikultural dalam berpolitik. Hasilnya menunjukkan, bahwa manajemen multikultural sebagai pengelolaan pandangan hidup dapat mewujudkan kesadaran berpolitik. Dengan adanya multikultural, maka dapat melahirkan pandangan dan system politik yang sehat, sehingga terciptanya rasa aman, nyaman dan damai dalam kehidupan berbangsa dan bernegara, sehingga penulis dapat menyarankan jika ingin kondisi perpolitikan berlangsung secara aman, damai dan harmonis, maka tingkatkan manajemen multikultural dalam masyarakat

Kata kunci: Multikultural; Manajemen; Politik. 
Khairiah:

Manajemen Multikultural dalam Berpolitik

\section{Pendahuluan}

Politik sering dimaknai dengan konotasi negative dan kotor. Politik merupakan kenyataan hidup yang harus dihadapi dan dijalankan oleh setiap orang selama manusia berinteraksi secara sosial, politik sebagai alat berinteraksi sosial antara manusia dengan manusia, sehingga setiap manusia mau tidak mau harus menggunakan politik (kekuasaan dan pengaruh) sebagai alat berinteraksi. Setiap berinteraksi manusia membawa minat, kepentingan, persepsi dan tujuan yang berbeda-beda, sehingga proses pengaruh mempengaruhi dalam organisasi merupakan hal yang wajar dalam kehidupan organisasi. Politik adalah suatu kenyataan sosial yang harus dihadapi, meskipun kita tidak suka politik, kita tetap tidak bisa menghindar dari politik (Dahl, 1999) ${ }^{1}$ politik sebagai jaringan interaksi antarmanusia dengan kekuasaan diperoleh, ditransfer dan digunakan yang berbeda dianggap bertentangan dengan keberagaman budaya dalam masyarakat, maka manajemen multikultural merupakan solusi pembelajaran dan penyelesaian berinteraksi dalam pekerjaan. Sehingga terbentuknya masyarakat demokratis, ditegakkannya hukum dalam penyelenggaraan pemerintahan,

${ }^{1}$ Dahl, R., Analisis Politik Modern (Terjemahan), Bumi Aksara, Jakarta, 1994. terwujudnya rasa aman, damai, pemerataan ekonomi, dan kesejahteraan ke seluruh lapisan masyarakat (Zubaedi, 2006: Ibnu A. I., 2016; khairiah, 2020) ${ }^{2}$

Studi tentang manajemen multikultural dalam berpolitik sejauh ini menunjukkan bersifat evaluatif atas situasi dan dampaknya. Pertama, studi memotret dampak dan akibat dari politik kekuasaan (Drory, 1993: Bolman, 1991) ${ }^{3}$ kedua studi yang melihat bagaimana politik dengan jaringan berinteraksi sosial yang dialami oleh masyarakat yang mengubah tatanan sosial, yang membangun penghayatan hidup bersama dalam keberagaman. (Aqil Irham, 2013). ${ }^{4}$ Kedua kecenderungan studi tersebut belum membicarakan salah satu faktor penting dalam kehidupan sosial yakni manajemen multikultural sebagai cerminan masyarakat, yang memberikan

${ }^{2}$ Zubaedi. (2006). Pendidikan Berbasis Masyarakat, Yogyakarta: Pustaka Pelajar, Baca Juga: R Ibnu Ambarudin. (2016). Pendidikan Multikultural Untuk Membangun Bangsa Yang Nasionalis dan Religius Jurnal Civics, Vol.13, No.1, Juni 2016, Baca Juga: Khairiah, (2020), Multikultural Dalam Pendidikan Islam, Bengkulu: Penerbit CV. Zigie Utama.

${ }^{3}$ Drory. Perceived Political Climate and Job Attitudes. Organizational Studies, 1993;14(1):59-71. Baca Juga: Bolman, L.G \& Deal, T.E. Reframing Organizations: Artistry, Choice, and Leadership, Jossey-Bash Publishers, San Francisco, 1991

${ }^{4}$ Aqil Irham. (2013). Kebijakan Politik Multikultural dan Upaya Mencegah Konflik Sosial Berbau SARA Belajar Kasus Waypanji Lampung Selatan Jurnal TAPIs, Vol.9, No.1, Januari-Juni 2013, Baca Juga: NicoFergiyono,https://nicofergiyono.blogspot.com/ 2013/09/politik-multikulturalisme-diindonesia.html 
ruang identitas partikuler, ${ }^{5}$ sehingga dapat menjamin otensititas kehidupan demi terwujudnya masyarakat yang damai, aman dan harmonis, sebagai jawaban atas masalah politik.

Tulisan ini berupaya untuk melengkapi penelitian yang ada dengan mengkaji manajemen multikultural dalam berpolitik. Dengan mencermati secara seksama dampak kondisi perpolitikan dalam masyarakat multikultural di Indonesia (Said Aqil Siradj, 1999; Zubaedi, 2007). ${ }^{6}$ Menggunakan metode kualitatif deskriptif, sehingga multikultural dapat diterima sebagai konsep yang mampu menjawab tantangan perubahan zaman, dengan mengakui perbedaan serta mendorong terwujudnya pluralitas universal dalam konteks keIndonesiaan berbhinnika tunggal ika, sebagai corak kehidupan berbangsa dan bernegara.

Tulisan ini berangkat dari asumsi bahwa politik yang terjadi di mayarakat multikultural telah dikuti dengan perbedaan SARA, sehingga seringkali memicu timbulnya konflik dan ketegangan, seperti pemilu, pilkada, pileg dan pilpres, bahkan politik kampus ketika penjaringan bakal calon rektor pada

\footnotetext{
${ }^{5}$ RezaA.AWattimena,https://rumahfilsafat. com/2009/11/29/politik-multikulturalisme/

${ }^{6}$ Said Aqil Siradj. (1999). Islam Kebangsaan: Fiqh Demokratik Kaum Santri, Jakarta: Pustaka Ciganjur, h. 203, Baca Juga: Zubaedi. (2007). Islam dan Benturan Antar Peradaban, Yogyakarta: Ar Ruzz Media, h. 54
}

Perguruan Tinggi (PT) menjadi ajang konflik dan perdebatan sesama simpatisan masing-masing calon, seperti; kampanye hitam, penghujatan, fitnah dan berita hoks, baik melalui media cetak maupun media elektronik. ${ }^{7}$ Perubahan sikap dan perilaku akibat perpolitikan membutuhkan disrupsi dalam masyarakat multikultural, dengan kata lain adopsi suatu keberagaman kebudayaan dalam masyarakat multikultural membutuhkan kekuatan untuk memaksakan adanya kesadaran baru atas suatu perubahan sosial. Manajemen multikultural dapat dintegrasikan dalam kehidupan sosial masyarakat secara meluas atas kesadaran fungsi yang diberikan oleh manajemen multikultural dalam berpolitik di Indonesia.

\section{Pembahasan}

\section{Pengelolaan Multikultural dalam}

\section{Kehidupan Berpolitik}

Multikultural sebagai ideologi menjadi alat atau wahana untuk meningkatkan derajat manusia dan kemanusiaannya. Kesamaan dan kesederajatan dijamin secara hukum oleh Negara, termasuk di dalam berpolitik, hukum dan pemerintahan. ${ }^{8}$ Melalui pengelolaan kebijakan pemerintah dengan persetujuan DPR, menetapkan Undang-

${ }^{7}$ Data Biro Administrasi Umum Akademik dan Kemahasiswaan (AUAK) Institut Agama Islam Negeri (IAIN) Bengkulu Tahun 2017.

8 , Pasal 27 dan 28 Undang-Undang Dasar Negara Republik Indonesia Tahun 1945 
Khairiah:

Manajemen Multikultural dalam Berpolitik

undang Nomor 3 Tahun 1985 mengharuskan partai-partai politik harus menerima Pancasila sebagai asas tunggal. Maksudnya penyeragaman ideologis melalui pancasila, yang telah menjadi konsensus nasional. Dengan satu tujuan menghindari permasalahan perbedaan ras, keyakinan agama, suku dan antar golongan disebut SARA. Karena permasalahan SARA sangat sensitif di Indonesia sering menimbulkan konflik sosial.

Konflik sosial yang bermuatan SARA tidak dapat dihindari, seperti: pada Tahun 1992 terjadi konflik antara kaum muslimin dan nonmuslim di Jakarta, Tragedi Aceh (1999), Ambon (1999), Maluku (1998-2000), Poso (2000), Sampit (2001), Papua (2001-2019). ${ }^{9}$ Kemudian pemerintah kembali membuat kebijakan pengelolaan organisasi sosial dan politik (Orsospol) diseragamkan, dengan tujuan keamanan dalam negeri menjadi aman, peleburan partai politik agar pemerintah dapat mengontrol parpol, Pembangunan pondasi kekuasaan, peran kepresidenan menjadikan semakin kuat dalam Negara dan Masyarakat multikultural. Dengan kata lain, setiap organisasi sosial dan perpolitikan harus menerima Pancasila

\footnotetext{
${ }^{9}$ https://today.line.me/id/pc/article/Renteta $\mathrm{n}+$ Tragedi+Berdarah+di+Papua+dari+Wasior+hing ga+Puncak+Illaga-vzvRao. Baca Juga: https://kronologis-kerusuhan-ambon.blogspot.com/. Baca Juga: https://id.wikipedia.org/wiki/Tragedi_Simpang_KK A.
}

sebagai satu-satunya asas dan dasar organisasi dan partai politik.

Kemajemukan atau multikultural sudah lama ada di negara ini, bahkan sebelum negara Indonesia terbentuk, para pendiri bangsa menyadari bahwa keberagaman merupakan realita sosial yang tidak dapat dihindari. Mereka menyadari keragaman budaya merupakan kekuatan dalam mempertahankan Negara Kesatuan Republik Indonesia (NKRI). Namun jika multikultural tidak dikelola dengan baik dan bijaksana, maka berpotensi terjadi konflik, sehingga dapat merusak keutuhan bangsa Indonesia, dan jika keberagaman budaya dikelola dengan baik, maka keberagaman budaya menjadi asset kekayaan bangsa Indonesia. Karena masyarakat mejemuk menganggap perbedaan merupakan sesuatu hal yang alamiah, dan tidak dapat di hindari. ${ }^{10}$ Multikultural tumbuh secara organik, sehingga pengakuan nilai-nilai lokal berdampingan dengan nilai-nilai lain. ${ }^{11}$ catatan sejarah multikultural diawali dengan lahirnya sumpah pemuda Tahun 1928, dengan satu tanah air, satu bangsa dan satu bahasa Indonesia ketika dan

\footnotetext{
${ }^{10}$ Bhermansyah,https://www.kompasiana.c om/bhermansyah/550e29f1a33311a42dba7fac/mult ikulturalisme-di-alam-demokrasi.

${ }^{11}$ Wahid, Abdurrahman. (2003). Hubungan antar-agama, Demensi Internal dan Eksternalnya di Indonesia dalam Dialog: Kritik dan Identitas Agama, Seri Dian I Tahun I. Yogyakarta: Penerbit Dian / Interfidei,t.t.), h.12
} 
setelah Indonesia Merdeka, keberagaman tersebut diikat dalam hokum formal. ${ }^{12}$

Multikultural dalam berpolitik, seperti: Pilpres, pilkada, dan pileg, semua warga Negara, masyarakat Indonesia mempunyai kesempatan untuk dipilih dan memilih, karena system politik Indonesia menganut demokrasi pancasila. Demokrasi, sejatinya memiliki nilai-nilai yang berlaku secara universal, yaitu nilai kebebasan, persamaan, kedaulatan rakyat, toleransi dan peacefull conflict resolution (menyelesaikan konflik dengan damai). ${ }^{13}$

Berdasarkan nilai-nilai tersebut di atas, sebagai sebuah bangsa yang mempraktekan demokrasi dalam tatanan politik, sebenarnya tidak ada lagi persoalan dan konflik tentang keberagaman untuk ikut dalam panggung demokrasi. Memilih calon berdasarkan kesamaan golongan atau kelompok bukanlah pilhan rasional, yang harus di lihat ketika memilih adalah track record, kapasitas, kapabilitas serta visi dan misinya dalam membangun daerah, bangsa dan Negara kedepan. Perasaan primordialisme atau etnisitas dalam perhelatan demokrasi, tidak relevan lagi di alam demokrasi, basis suara yang hanya mengandalkan loyalitas atau sentimen

\footnotetext{
${ }^{12}$ Pembukaan Undang-Undang Dasar 1945, Batang Tubuh UUD 1945 terutama Pasal 32, Pasal 18 B

${ }^{13}$ Wahid, Abdurrahman. Hubungan antaragama,... h.12
}

etnisitas merupakan pola-pola lama, dan tidak dipakai lagi di negara demokrasi. Karena prinsip demokrasi dalam tata kehidupan dunia, masyarakat dan pendidikan harus etis, sehingga semua pihak menyadari pluralisme ternyata berkenaan dengan hak hidup semua kelompok masyarakat yang ada dalam suatu komunitas. ${ }^{14}$ Dan nilai-nilai tersebut perlu masuk kedalam system pendidikan.

Kebijakan dalam bidang pendidikan merupakan upaya pengelolaan pendidikan yang baik, sehingga setiap orang dapat masuk kedalamnya dan memperoleh perlakuan sederajat dan seimbang, sesuai kapasitasnya masing-masing. Pendidikan masih dipandang sebagai upaya menyelematkan kelangsungan hidup manusia. Pendidikan merupakan bagian tanggungjawab penyelenggara negara, sehingga maju mundurnya suatu negara sangat ditentukan oleh mampu tidaknya Negara menyelenggarakan pendidikan. Khairiah menyebutkan Negara maju dipengaruhi pendidikan maju. ${ }^{15}$

${ }^{14}$ R Ibnu Ambarudin. (2016). Pendidikan Multikultural Untuk Membangun Bangsa Yang Nasionalis dan Religius Jurnal Civics, Vol.13, No.1, h.31

${ }^{15}$ Khairiah, K., (2018). Kesempatan Mendapatkan Pendidikan Dalam Kajian Tingkat Pendidikan dan Pendapatan Keluarga, Yogyakarta: Pustaka Pelajar, h. 159, Baca Juga: Khairiah, K. (2019). Evaluasi Program Tridarma Perguruan Tinggi dalam Pengembangan Sumberdaya Manusia Menuju World Class University Pada Institut Agama Islam Negeri Bengkulu. Nuansa. 
Khairiah:

Manajemen Multikultural dalam Berpolitik

Penyelenggaraan pendidikan dimunculkan karena adanya struktur. Struktur menggambarkan kewenangan dan tingkatan, tingkatan kewenangan menggambarkan tingkat legalitas kekuatan/ kekuasaan atas orang, kelompok dan kelembagaan. Kekuasaan dalam pendidikan adalah sebuah bentuk legalitas terhadap kepemimpinan yang dijalankannya, legalitas artinya kepemimpinan dalam organisasi pendidikan adalah kekuasaan individual ataupun kolektivitas. Kekuasaan dan pendidikan, memiliki dua makna, pertama kekuasaan sebagai bentuk kewenangan dalam kelembagaan pendidikan, dan kedua sebagai pendidikan melahirkan kekuasaan yang baik.

Untuk mewujudkan struktur organisasi yang memiliki legalitas yang baik, ${ }^{16}$ Untuk menghindari konflik dan perbedaan pilihan di kampus, maka Menteri Agama membuat kebijakan, terkait mekanisme dan penetapan pimpinan perguruan tinggi diambil alih oleh pemerintah pusat yaitu kementerian Agama, sebagai berikut: (1) Menteri membentuk Komisi Seleksi untuk

\footnotetext{
${ }^{16}$ Peraturan Menteri Agama Nomor 11 Tahun 2014 Tentang pengangkatan dan pemberhentian Rektor dan Ketua pada Perguruan Tinggi Keagamaan yang diselenggarakan oleh Pemerintah. Dan Peraturan Menteri Agama RI Nomor 68 Tahun 2015 Tentang pengangkatan dan pemberhentian Rektor dan Ketua pada Perguruan Tinggi Keagamaan yang diselenggarakan oleh Pemerintah.
}

melakukan penyeleksian calon Rektor/Ketua yang ditetapkan melalui Keputusan Menteri. (2) Anggota Komisi Seleksi sebagaimana dimaksud pada ayat (1) berjumlah ganjil paling sedikit 7 (tujuh) orang yang terdiri dari ketua dan anggota. (3) Komisi Seleksi dapat melakukan uji kepatutan dan kelayakan terhadap calon Rektor/Ketua. (4) Komisi Seleksi menyerahkan Calon Rektor/Ketua kepada Menteri paling banyak 3 (tiga) orang. Sehingga budaya kampus menjadi kondusif terhindar dari politik praktis. Kebijakan tersebut, Menteri Agama mengakomodir kepentingan setiap kelompok identitas budaya, dengan memberikan ruang, tempat berdialog dan berkompetisi dengan kepentingan identitas budaya masing-masing, untuk menjadi seorang pimpinan. ${ }^{17}$

Interaksi calon pimpinan dalam organisasi, setiap calon menggunakan kekuasaan dan pengaruh untuk dapat memenuhi tujuannya. Kekuasaan didefinisikan sebagai peluang seseorang dalam interaksi sosialnya berada di posisi memenangkan keinginannya meski ada hambatan dari pihak lain. Keuntungan

\footnotetext{
${ }^{17}$ RezaA.Awattimena,https://rumahfilsafat. com/2009/11/29/politik-multikulturalisme/, Baca Juga: Khairiah, K., (2019) Implementasi EPerformance dan Sasaran Kinerja Pegawai Dalam Upaya Peningkatan Kinerja Pegawai Pada Institut Agama islam Negeri Bengkulu. In: International Seminar on Islamic Studies, 28 Maret 2019, IAIN Bengkulu.
} 
memiliki kekuasaan adalah dapat melakukan lebih banyak kebaikan. ${ }^{18}$ Kekuasaan merujuk kepada ketersediaan sumber daya, pengaruh merujuk kepada tindakan atau praktik. Pengaruh dapat didefinisikan sebagai penggunaan kekuasaan atau otoritas untuk mempersuasi orang lain agar mereka mengikuti kehendak si pengguna kekuasaan. Pengaruh adalah efek dari tindakan agen tehadap pihak lain (target). Secara sekuensial dapat dikatakan bahwa kekuasaan menimbulkan pengaruh dan akhirnya pengaruh mempengaruhi tindakan orang lain (Yukl, 1994) ${ }^{19}$

Namun demikian, beberapa rujukan tentang perilaku politik sering mempertukarkan istilah kekuasaan dan pengaruh. Asumsi dasar organisasi sebagai entitas politik yaitu: (1) organisasi adalah koalisi yang terdiri dari berbagai individu dan kelompok dengan berbagai kepentingan, (2) dalam organisasi selalu ada potensi perbedaan menyangkut kepribadian, keyakinan, kepentingan, sikap, persepsi, dan minat dari para anggotanya, (3) kekuasaan memainkan peranan penting dalam memperebutkan

\footnotetext{
${ }^{18}$ Drory. Perceived Political Climate and Job Attitudes. Organizational Studies, 1993;14(1):59-71, Baca Juga: Strauss. A. et al .The Hospital and Its Negotiated Order, in Friedson, Eliot, The Hospital in Modern Society, Free Press J/Glencoe, New York, 1963:147-69.

${ }^{19}$ Yukl, G. A. Leadership in Organizations, Prentice Hall Inc, New Jersey, 1994.
}

sumber daya, (4) tujuan organisasi, pengambilan keputusan dan proses manajemen lainnya adalah hasil dari bargaining, negosiasi, dan brokering dari berbagai faksi peserta, (5) karena keterbatasan sumber daya dan setiap aktor berebut kepentingan, maka konflik adalah wajar (natural) dalam kehidupan organisasi. $^{20}$

\section{Pengelolaan Keberagaman Budaya} dalam Berpolitik di Indonesia

Politik multikultural di Indonesia mulai diperbincangkan, masa Abdur Rahman Wahid menjabat sebagai presiden. Gus dur merupakan tokoh pluralisme yang menghargai dan menjunjung tinggi keberagaman budaya di Indonesia, seperti pengakuan keberadaan dan eksistensi Tionghoa ditengah warga pribumi, bahkan keturunan Tionghoa mendapatkan kesempatan untuk berperan serta dalam pemerintahan. Selain itu, Konghuchu, agama Tionghoa diakui sebagai agama resmi ke enam di Indonesia pada masa pemerintahannya, yang menjadi landasannya adalah terbangunnya politik multikultural, yaitu terbangunnya penghayatan hidup bersama, dan keberagaman sebagai bagian dari hidup

\footnotetext{
${ }^{20}$ Drory. Perceived Political Climate and Job Attitudes. Organizational Studies, 1993;14 (1), h. 59-71.
} 
Khairiah:

Manajemen Multikultural dalam Berpolitik

bersama yang perlu dihayati secara konsekuen. $^{21}$

Multikultural di Indonesia di awali dari historis giografis, dan keterbukaan terhadap kebudayaan luar, sehingga latar belakang dan kondisi giografis dapat terjadi segmentasi, sehingga terciptanya struktur sosial yang bersifat non komplementer, kurang mengembangkan konsensus diantara anggota terhadap nilainilai yang bersifat dasar, integrasi sosial tumbuh di atas paksaan, dan dominasi politik dari satu kelompok atas kelompok lainnya. (Pierre L. Van den Berghe, 1990). ${ }^{22}$

Sejalan dengan hal tersebut, maka peran bangsa Indonesia dalam menghadapi multikultural, harus beradaptasi dengan lingkungan dan memiliki integritas yang tinggi. Dengan asumsi pengelolaan politik yang sehat, melahirkan sistem politik yang sehat pula. Perpolitikan di Indonesia diikat dengan peraturan dan perundangundangan, dengan tujuan kebersihan politik sehingga tidak membahayakan khalayak, dan tercipta rasa aman dan

\footnotetext{
${ }^{21}$ NicoFergiyono,https://nicofergiyono.blo gspot.com/2013/09/politik-multikulturalisme-diindonesia.html (Diakses pada tanggal 1 Januari 2020, pukul 14.00)

${ }^{22}$ Van den Berghe, Pierre L. 1990. "From the Popocatetepl to the Limpopo." pages 410-431 in Bennett M. Berger, editor, Authors of Their Own Lives: Intellectual Autobiographies by Twenty American Sociologists. University of California Press. Baca Juga: van den Berghe, Pierre (1989). Stranger in their Midst. University Press of Colorado. ISBN 0870812025.
}

nyaman, seperti: Undang-undang Nomor 27 tentang MPR, DPR, DPD dan DPRD. Pada pasal 15 ayat 1 menyebutkan empat pilar kehidupan berbangsa dan bernegara, yaitu; Pancasila, Undang-undang Dasar 1945, Negara Kesatuan Republik Indonesia dan Bhinneka Tunggal Ika.

Empat pilar tersebut menjamin terwujudnya kebersamaan dalam hidup bernegara. Karena pilar tersebut merupakan tiang penyangga suatu bangunan, sehingga bangunan mampu berdiri kokoh. Rakyat merasa aman dan nyaman terlindungi, sehingga merasa tenteram dan menikmati kehidupan berbangsanya secara optimal.

Politik yang gemilang dibarengi implementasi yang matang, tentunya mewujudkan kesejahteraan sosial, terciptanya perdamaian, rasa persatuan dan kesatuan Negara Republik Indonesia. Keberagaman budaya dalam berpolitik, menurut Azyumardi pada dasarnya pengelolaan pandangan dunia yang dapat diterjemahkan dalam berbagai kebijakan kebudayaan yang menekankan penerimaan terhadap realitas keagamaan, pluralitas dan multikultural yang terdapat dalam kehidupan masyarakat. $^{23}$ Multikulrural

\footnotetext{
${ }^{23}$ Azra, Azumardi. (2013). Identitas dan Krisis Budaya, Membangun Multikulturalisme Indonesia, From http:/budpar.go.id/ agenda/precongress/makalah/abstrak $\quad 158 \quad \% \quad 20$ azra.htm, akses 10 Maret 2013. Baca Juga: Azra, Azyumardi. 2007. Identitas dan Krisis Budaya, Membangun Multikulturalisme Indonesia.
} 
sebagai kebudayaan dan konsepnya dibatasi muatan nilai atau memiliki kepentingan tertentu (Zakki Mubarak' 2008). ${ }^{24}$ Multikultural sebagai pandangan dunia yang diwujudkan dalam kesadaran berpolitik. $^{25}$

Parekh, (1997) yang dikutip dari Azra, menyebutkan masyarakat multikultural adalah suatu masyarakat yang terdiri dari beberapa macam komunitas budaya dengan segala kelebihannya, dengan sedikit perbedaan konsepsi mengenai dunia, suatu sistem arti, nilai, bentuk organisasi sosial, sejarah, adat serta kebiasaan. ${ }^{26}$ Multikultural mencakup suatu pemahaman, penghargaan serta penilaian atas budaya seseorang, serta suatu penghormatan dan keingintahuan tentang budaya etnis orang lain (Lawrence Blum, dikutip Lubis, 2006). ${ }^{27}$ Multikultural sebagai sebuah ideologi yang mengakui dan mengagungkan

${ }^{24}$ Mubarak, Zakki, dkk. (2008). Buku Ajar II, Mata Kuliah Pengembangan Kepribadian Terintegrasi (MPKT) cet. Kedua. 2008: Manusia, Akhlak, Budi Pekerti dan Masyarakat, Depok: Penerbit FE UI

${ }^{25}$ Azyumardi, Azra. Identitas dan Krisis Budaya, Membangun Multikulturalisme Indonesia. http://www.kongresbud.budpar.go.id/58\%20ayyum ardi\%20azra.htm.

${ }^{26}$ Azyumardi, Azra. Identitas dan Krisis Budaya, Membangun Multikulturalisme Indonesia. http://www.kongresbud.budpar.go.id/58\%20ayyum ardi\%20azra.htm.

${ }^{27}$ Lubis, $\quad$ Akhyar Yusuf, 2006. Deskontruksi Epistemologi Modern. Jakarta: Pustaka Indonesia Satu, 2006, h. 174. perbedaan dalam kesederajatan baik secara individual maupun secara kebudayaan. ${ }^{28}$

Pengelolaan multikultural mencakup gagasan, tatacara pandang, kebijakan, penyikapan dan tindakan masyarakat suatu negara, yang majemuk dari segi etnis, budaya, adat istiadat, agama, namun mempunyai cita-cita yang sama untuk mengembangkan semangat kebangsaan dan mempunyai kebanggaan untuk mempertahankan kemajemukan tersebut. ${ }^{29}$ Pada prinsipnya adalah dasar yang harus dijadikan acuan setiap budaya memiliki nilai sendiri-sendiri. Setiap orang atau kelompok berhak hidup menurut budaya yang mereka yakini secara otentik. Pemerintahan multikultural adalah cerminan dari masyarakat Indonesia yang juga multicultural, sehingga pemerintahan multikultural bisa menjamin otentisitas kehidupan dari individu ataupun kelompok yang dipimpinnya memiliki pandangan yang seragam, mengakui perbedaan dalam berpolitik, seutuhnya dan keefektifan seseorang (Henry). ${ }^{30}$ Pengakuan keberagaman budaya hanya dapat diperoleh melalui pendidikan.

\footnotetext{
${ }^{28}$ Suparlan, Parsudi. (2002). Menuju Masyarakat Indonesia yang Multikultural, Simposium Internasional Bali ke-3, Jurnal Antropologi Indonesia, Denpasar Bali, h. 16-21

${ }^{29}$ Harahap, Ahmad Rivai, (2004), Multikulturalisme dan Penerapannya dalam pemeliharaan kerukunan Umat Beragama.

${ }^{30} \mathrm{http}: / /$ pengertiandefinisi.com/pengertianintegritas-menurut-pandangan-para-ahli/
} 
Khairiah:

Manajemen Multikultural dalam Berpolitik

Pendidikan dapat membantu mempersiapkan generasi muda untuk menghadapi masyarakat multicultural, karena pendidikan berfungsi mengembangkan kemampuan dan membentuk watak serta peradaban bangsa yang bermartabat dalam rangka mencerdaskan kehidupan bangsa. ${ }^{31}$ Pandangan tersebut lebih fokus pada kajian pendidikan multikultural. Pendidikan multikultural adalah pendidikan nilai yang harus ditanamkan pada generasi muda agar memiliki persepsi dan sikap multikulturalistik, agar terbiasa hidup berdampingan dalam keberagaman watak dan kultur, agama dan Bahasa, menghormati hak setiap warga Negara tanpa membedakan etnik mayoritas atau minoritas, dan dapat bersama-sama membangun kekuatan bangsa sehingga diperhitungkan dalam percaturan global dan nation dignity yang kuat.

Ada lima alasan pendidikan multikultural diperlukan sebagai berikut: (1) perubahan kehidupan manusia Indonesia yang disebabkan oleh kemajuan ekonomi memperbesar jurang sosial antara kelompok atas dengan kelompok bawah; (2) adanya perpindahan dan mobilitas penduduk yang cukup tinggi yang

${ }^{31}$ Undang-undang Nomor 20 Tahun 2003 Tentang Sistem Pendidikan Nasional, Baca Juga: Khairiah, K. (2018). Strategy of Early Childhood Learning Model Development. Al Fitrah: Journal Of Early Childhood Islamic Education, 1(2), 47-53. menyebabkan adanya pertemuan yang sering dan intens antara kelompok dengan budaya yang berbeda; (3) semakin terbukanya daerah-daerah pedesaan; (4) berbagai konflik social budaya yang muncul akhir-akhir ini memperlihatkan adanya kesalahpahaman budaya yang sangat besar antar kelompok yang bertikai; (5) menghapus mitos dan tafsiran sejarah yang tidak menguntungkan bagi persatuan bangsa. Pengembangan pendidikan multikulturalisme harus didasarkan pada tiga prinsip, sebagai berikut: (1) keragaman budaya menjadi dasar dalam menentukan filsafat; (2) keragaman budaya dijadikan sebagai dasar dalam mengembangkan berbagai komponen kulrikulum seperti tujuan, konten, proses dan evaluasi; (3) budaya di lingkungan pendidikan adalah sumber belajar dan objek studi yang harus dijadikan bagian dari kegiatan belajar para pemuda. ${ }^{32}$ Sehingga politik multikultural di Indonesia menjadi berkembang melalui pendidikan dengan menanamkan nilai-nilai kesetaraan dan kebersamaan dalam keberagaman pada dunia pendidikan. Pandangan politik multikultural di Indonesia khususnya pada dunia pendidikan tersebut menumbuhkan kesadaran bagi sivitas akademika, bahwa nilai kebersamaan menjadi sangat penting,

\footnotetext{
${ }^{32}$ https://www.kompasiana.com/cpfocvian ny/56657fc45fafbdd5094bc78f/multikulturalismeindonesia
} 
sehingga proses pendidikan tertentu tidak merasa lebih tinggi dari proses pendidikan yang lain, kerja kooperatif dan kolaboratif berkembang secara aktif dan efektif, serta peningkatan pemahaman, bahwa setiap manusia memiliki kemerdekaan masingmasing yang perlu dihargai, sehingga budaya kampus menjadi nyaman, damai dan kondusif.

\section{Penutup}

Multikultural dalam berpolitik merupakan konsep atau upaya mewujudkan kemampuan menjawab tantangan perubahan zaman, dengan mengakui perbedaan dalam kesederajatan serta mendorong terwujudnya pluralitas universal dalam konteks keindonesiaan berbhinneka tunggal ika. Jika keberagaman budaya dalam berpolitik dikelola dengan baik, maka tidak terjadi konflik social, sehingga dapat melahirkan pandangan politik yang sehat, serta dapat mewujudkan sistem politik yang sehat pula. Pengelolaan perpolitikan pada penyelenggaraan Negara Indonesia diikat dengan peraturan dan perundangundangan, seperti: Undang-undang Nomor 27 Tahun 2009 Tentang MPR, DPR, DPD dan DPRD, menyebutkan empat pilar kehidupan berbangsa dan bernegara, yaitu; Pancasila, Undang-undang Dasar 1945, Negara Kesatuan Republik Indonesia dan Bhinneka Tunggal Ika. Dengan tujuan mewujudkan politik yang bersih, tidak membahayakan kehidupan khalayak, sehingga terciptanya rasa aman, nyaman dan damai dalam kehidupan berbangsa dan bernegara. Dengan demikian penulis dapat menyarankan untuk studi selanjutnya dapat melakukan tentang etika berpolitik dalam multikultural.

\section{Pustaka Acuan}

Ambarudin, $\mathrm{R}$ Ibnu, "Pendidikan Multikultural Untuk Membangun Bangsa Yang Nasionalis dan Religius”. Jurnal Civics, Vol.13, No.1, 2016.

Aqil Irham, "Kebijakan Politik Multikultural dan Upaya Mencegah Konflik Sosial Berbau SARA Belajar Kasus Waypanji Lampung Selatan", Jurnal TAPIs, Vol.9, No.1, 2013.

Azyumardi, Azra. Identitas dan Krisis Budaya,

Membangun

Multikulturalisme

Indonesia. http://www.kongresbud.budpar.go.id/ 58\%20ayyumardi\%20azra.htm.

Bolman, L.G \& Deal, T.E. Reframing Organizations: Artistry, Choice, and Leadership, Jossey-Bash Publishers, San Francisco, 1991

Data Biro Administrasi Umum Akademik dan Kemahasiswaan (AUAK) Institut Agama Islam Negeri (IAIN) Bengkulu Tahun 2017. 
Khairiah:

Manajemen Multikultural dalam Berpolitik

Dahl, R., “Analisis Politik Modern (Terjemahan)", Jakarta: Bumi Aksara, 1994.

Drory, "Perceived Political Climate and Job Attitudes. Organizational Studies," 1993;14(1):59-71.

Harto, Kasinyo, "Model Pengembangan Pendidikan Agama Islam" Jakarta: PT. RajaGrafindo Persada, 2012 , "Model Pengembangan Pendidikan Agama Islam Berbasis Multikultural”, Jakarta: PT. Rajawal Press, 2014. Harahap, Ahmad Rivai, "Multikulturalisme dan Penerapannya dalam pemeliharaan kerukunan Umat Beragama”, (2004)

https://www.kompasiana.com/cpfocvianny /56657fc45fafbdd5094bc78f/multikult uralisme-indonesia

https://nicofergiyono.blogspot.com/2013/0

9/politik-multikulturalisme-di-

indonesia.html

https://rumahfilsafat.com/2009/11/29/

politik-multikulturalisme/

https://today.line.me/id/pc/article/Rentetan

+Tragedi+Berdarah+di+Papua+dari+

Wasior+hingga+Puncak+Illaga-

vzvRao.

https://kronologis-kerusuhan-

ambon.blogspot.com/.

https://id.wikipedia.org/wiki/Tragedi_Sim pang_KKA. https://www.kompasiana.com/bhermansya h/550e29f1a33311a42dba7fac/multiku lturalisme-di-alam-demokrasi.

https://www.kompasiana.com/cpfocvianny/5 6657fc45fafbdd5094bc78f/multikulturali sme-indonesia

http://pengertiandefinisi.com/pengertianintegritas-menurut-pandangan-paraahli/

https://rumahfilsafat.com/2009/11/29/politi kmultikulturalisme/ http://pengertiandefinisi.com/pengertianintegritas-menurut-pandangan-paraahli/ https://rumahfilsafat.com/2009/11/29/politi k-multikulturalisme/

Ibrahim, Rustam, "Pendidikan Multikultural: Pengertian, Prinsip dan Relevansinya dengan Tujuan Pendidikan Islam", Addin, Vol.7, No.1, 2013.

Irham, Aqil, "Kebijakan Politik Multikultural dan Upaya Mencegah Konflik Sosial Berbau SARA Belajar Kasus Waypanji Lampung Selatan." Jurnal TAPIs, Vol.9, No.1, 2013

Khairiah, K.," Kesempatan Mendapatkan Pendidikan Dalam Kajian Tingkat Pendidikan dan Pendapatan Keluarga," Yogyakarta: Pustaka Pelajar, 2018 http://repository.iainbengkulu.ac.id/32 $45 /$ 
,’Peningkatan Mutu Pendidikan

Melalui Implementasi Manajemen

Peningkatan Mutu Berbasis Sekolah (MPMBS) Pada MTsN Kota Bengkulu," Jurnal Nuansa, Volumen 11, Nomor 1 (2018), 11(1). https://ejournal.iainbengkulu.ac.id/ind ex.php/nuansa/article/view/1351 ,'Strategi of Early Childhood Learning Model Development," Al Fitrah: Journal of Early Childhood Islamic Education, 1(2), 47-53, 2018. https://ejournal.iainbengkulu.ac.id/ind ex.php/alfitrah/article/view/1333 ,'Pengaruh Struktur Organisasi (Organizational Structure), Kepuasan Kerja (Job Satisfaction) Terhadap Komitmen Organisasi (Organizational Comitmen) Pada Institut Agama Islam Negeri (IAIN) Bengkulu, Jurnal Nuansa, 10(1), 2017.

,'Evaluasi Program Tridarma

Perguruan Tinggi dalam

Pengembangan Sumberdaya Manusia Menuju World Class University Pada Institut Agama Islam Negeri Bengkulu” Nuansa, 12(1), 2019. https://ejournal.iainbengkulu.ac.id/ind ex.php/nuansa/article/view/2106

,'Dari Ruang Kelas: Evaluasi

Kelembagaan Pendidikan Islam Program Studi manajemen Pendidikan Islam Pascasarjana IAIN Bengkulu," Bengkulu: CV. Zigie. 2019. http://repository.iainbengkulu.ac.id/34 $16 /$

,'Implementasi E-Performance dan Sasaran Kinerja Pegawai Dalam Upaya Peningkatan Kinerja Pegawai Pada Institut Agama Islam Negeri (IAIN) Bengkulu. In: International Seminar on Islamic Studies, 2019. http://repository.iainbengkulu.ac.id/34 $18 /$

, Multikultural Dalam Pendidikan Islam, Bengkulu: Penerbit CV. Zigie Utama, 2020.

Langgulang, Hasan, Asas-Asas Pendidikan Islam. Jakarta: PT. Al Husna Zikra, 2000

Lubis, Akhyar Yusuf, Deskontruksi Epistemologi Modern. Jakarta: Pustaka Indonesia Satu, 2006.

Mahfud, Choirul, Pendidikan Multikultural, Yogyakarta: Pustaka Pelajar, 2009.

Mujid, Abdul, Ilmu Pendidikan Islam, Cetakan ke-2, Jakarta: Kencana, 2008. Mubarak, Zakki, dkk. Buku Ajar II, Mata Kuliah Pengembangan Kepribadian Terintegrasi (MPKT), Manusia, Akhlak, Budi Pekerti dan Masyarakat, Depok: Penerbit FE UI, 2008.

Muhammad Quraish Shihab, “Jilbab Pakaian Wanita Muslimat”, (Jakarta: Lentera Hati, 2014. 
Khairiah:

Manajemen Multikultural dalam Berpolitik

NicoFergiyono,https://nicofergiyono.blogs pot.com/2013/09/politik-

multikulturalisme-di-indonesia.html

Noer Aly, Hery, Ilmu Pendidikan Islam, Jakarta: PT. Logos Wacana Ilmu, 1999.

Pembukaan Undang-Undang Dasar 1945, Batang Tubuh UUD 1945 terutama Pasal 32, Pasal 18B

Peraturan Menteri Agama Nomor 11 Tahun 2014 Tentang pengangkatan dan pemberhentian Rektor dan Ketua pada Perguruan Tinggi Keagamaan yang diselenggarakan oleh Pemerintah.

Peraturan Menteri Agama RI Nomor 68 Tahun 2015 Tentang pengangkatan dan pemberhentian Rektor dan Ketua pada Perguruan Tinggi Keagamaan yang diselenggarakan oleh Pemerintah.

R Ibnu Ambarudin. (2016). Pendidikan Multikultural Untuk Membangun Bangsa Yang Nasionalis dan Religius Jurnal Civics, Vol.13, No.1, h.31

Siradj, Said Aqil. (1999). Islam

Kebangsaan: Fiqh Demokratik Kaum Santri.Jakarta: Pustaka Ciganjur

Suryana, Yaya dan A. Rusdiana. (2015).

Pendidikan Multikultural. Bandung: CV Pustaka Setia

Strauss. A. et al .The Hospital and Its Negotiated Order, in Friedson, Eliot, The Hospital in Modern Society, Free
Press J/Glencoe, New York, 1963:147-69.

Suparlan, Parsudi. (2002). Menuju Masyarakat Indonesia yang Multikultural, Simposium Internasional Bali ke-3, Jurnal Antropologi Indonesia, Denpasar Bali, 16-21 Juli 2002, 1987

Tobroni. (2008). Pendidikan Islam Paradigma Teologis. Malang: UMM Press

Undang-undang Nomor 20 Tahun 2003 Tentang Sistem Pendidikan Nasional, Van den Berghe, Pierre L. (1990). "From the Popocatetepl to the Limpopo." pages 410-431 in Bennett M. Berger, editor, Authors of Their Own Lives: Intellectual Autobiographies by Twenty American Sociologists. University of California Press. Baca Juga: van den Berghe, Pierre (1989). Stranger in their Midst. University Press of Colorado. ISBN 0870812025.

Wahid, Abdurrahman, "Hubungan antaragama, Demensi Internal dan Eksternalnya di Indonesia dalam Dialog: Kritik dan Identitas Agama”. Seri I Tahun I. Yogyakarta: Penerbit Dian / Interfidei, t.t., 2007

Yukl, G. A. Leadership in Organizations, Prentice Hall Inc, New Jersey, 1994. 